\title{
Nietzsche e "Hitler"
}

\author{
Alexander Nehamas
}

Resumo: Este artigo trata dos limites do imoralismo de Nietzsche, tomando como fio condutor a figura do heroi do mal. Defende-se a tese de que há um limite para esse imoralismo, na medida em que algumas questões devem permanecer na esfera de um tratamento moral, no sentido ligeiramente pejorativo que o termo recebeu entre os críticos da moralidade.

Palavras-chave: herói - imoralismo - virtude - fama

Nos anos da juventude, ainda veneramos e desprezamos sem a arte da nuance, que constitui nossa melhor aquisição na vida, e, como é justo, pagamos caro por atacar de tal modo com Sins e Nãos as pessoas e as coisas. Tudo se acha disposto para que o pior dos gostos, o gosto pelo incondicional, seja cruelmente logrado e abusado, até que o homem aprenda a pôr alguma arte nos sentimentos e, melhor ainda, a arriscar na tentativa do artificial: como fazem os veros artistas da vida (JGB/BM 31, KSA 5.49). ${ }^{1}$

A razão pela qual o nome de Hitler está entre aspas no título deste artigo é que não pretendo discutir as conexões históricas entre Nietzsche e o nacional-socialismo. Estou preocupado com uma questão mais abstrata e, segundo a minha opinião, mas premente. Ela diz respeito à atitude de Nietzsche em relação ao herói do mal - o grande indivíduo que, por quaisquer padrões razoáveis, pode ser um ser humano completamente inaceitável: o tipo de pessoa que evoca

* Artigo publicado originalmente em: The Southern Journal of Philosophy (1999), Vol. XXXVII, Supplement: p. 1-17. Tradução de Alice Medrado. Revisão técnica de Rogério Lopes.

** Professor da Princeton University, EUA.

Correio eletrônico: nehamas@princeton.edu

1 Todas as traduções das passagens das obras publicadas de Nietzsche são de autoria de Paulo César de Souza. 
mesmo entre aqueles de nós que compartilham, ou talvez (ao assim reagir a tal questão) meramente dizem compartilhar da repulsa do próprio Nietzsche por valores e estimativas morais. A intenção é que "Hitler" represente todos esses personagens. Mas Hitler constitui a instância mais incisiva de tal heroi do mal - e é por essa razão que usei seu nome no título e não, por exemplos, os nomes de Gengis Khan, Diocleciano. É nele que também nós, nietzschianos, inevitavelmente pensamos quando abordamos ou tentamos bordejar o problema dos heróis do mal e de nossas reações a eles.

A questão que continua martelando, não só no fundo da minha mente, é a seguinte: "Nietzsche aprovaria 'Hitler'?" Esta é uma questão que eu, pelo menos, nunca enfrentei completamente. A maioria daqueles que tratam dela - a menos que estejam dispostos a conceder a J.P. Stern que "o pathos de autenticidade pessoal... foi o bastião que guiou o fascismo e o nacional socialismo. Nenhum homem se aproximou tanto da criação pessoal de 'valores' quanto A. Hitler" ${ }^{\prime 2}$ - me parece evitar uma confrontação direta com ela. Eu não vou mencionar autores porque seria absurdo de minha parte acusar outros de fazer, mesmo que só em parte, o que eu não fiz de forma alguma. A questão que interessa não é mostrar que outros fracassaram. O que interessa é mostrar que $e u$ fracassei, e começar, ainda que de forma inadequada, a me confrontar diretamente com essa questão. Nesta altura, eu não sei para onde essa confrontação direta nos conduzirá.

Qual, exatamente, é o problema do heroi do mal? Vamos começar por uma abordagem indireta. No pensamento grego antigo, havia um acordo universal de que o que distingue os seres humanos entre si é a qualidade chamada areté. Apesar de que costumamos traduzir essa palavra por "virtude", o fato de que animais e mesmo objetos inanimados a exibem mostra que uma melhor tradução seria, precisamente, "distinção", a qualidade que faz com que alguém seja

2 STERN, J. P. A Study of Nietzsche Cambridge: Cambridge University Press, 1979, p. 117. 
Nehamas, A.

um membro proeminente dentro de algum grupo. Areté é o que faz com que algo seja justificadamente notável. Mas essa ideia levanta um sério problema, com cuja discussão nos deparamos de forma recorrente na filosofia grega ${ }^{3}$.

Ser distinto, proeminente e justificadamente renomado envolve três elementos: os traços internos que capacitam certas pessoas a serem proeminentes; a reputação efetiva de que essas pessoas gozam; e o público que deve apreciá-las. Em Homero, esses três elementos são harmônicos, e a areté é, portanto, quase um sinônimo de "fama" [kleos]. Mas e se este não for o caso? E se alguém tem os traços corretos, mas as pessoas não conseguem apreciá-los, como o Sócrates de Platão, que foi tomado por seus contemporâneos como sendo o contrário do que realmente era - um vilão ao invés de um ser humano nobre (tal qual Platão o via)? A estrutura psicológica, a alma que fez de Sócrates um ser humano magnífico aos olhos de Platão, era invisível para seus concidadãos. A estrutura interna e a face externa da areté se separaram. Na República, Platão tentou juntá-las novamente. Ele fez com que aqueles cujas almas são realmente distintas - os filósofos - fossem os legisladores, e, portanto, os cidadãos mais proeminentes de um estado cuja população é educada de modo a valorizar a coincidência de uma alma harmônica e uma posição de importância e realização públicas.

Mesmo se rejeitamos os valores particulares de Platão, podemos reconhecer o brilhantismo de sua concepção. Mas mesmo se aceitamos seus valores, devemos reconhecer sua impraticabilidade, sua pureza etérea que a coloca além do amplo alcance das perturbadoras vicissitudes da história. Carente de uma solução que seja tanto correta quanto praticável, no entanto, o problema antigo permanece: o que torna um ser humano excelente? O tipo correto de alma, que ninguém

3 Para uma discussão pormenorizada dessa questão, ver meu artigo: NEHAMAS, Alexander. The Art of Living: Socratic Reflections from Plato to Foucault Berkeley: University of California Press, 1998, cap. 3.

244 Cad. Nietzsche, Guarulhos/Porto Seguro, v.37, n.1, p. 242-268, 2016. 
talvez possa sequer conhecer ou apreciar? Ou a realização de grandes feitos que façam a diferença, que fazem com que alguém se eleve, se torne parte da história e, nos melhores casos, seja imortalizado de acordo com os métodos de um mundo que, para o bem ou para o mal, não é mais aquele de Homero? Contanto que as duas coisas possam divergir, uma boa pessoa não precisa ser grande e uma grande pessoa não precisa ser boa. É assim que o problema do heroi do mal vem à tona.

Essa concepção grega sobre o que distingue alguns seres humanos dos outros e os problemas que ela gera estão no coração do pensamento de Nietzsche. O "heroi trágico" de O Nascimento da Tragédia, os "exemplares" de Schopenhauer como Educador, os "espíritos livres" de Humano, demasiado humano e A Gaia Ciência, o "Übermensch" de Assim falou Zaratustra (tanto quanto, ou ainda mais, o próprio Zaratustra), os "nobres" de Além de Bem e Mal, os "senhores" de Genealogia da Moral, os "indivíduos" de Crepúsculo dos Ídolos, e finalmente sua própria figura em Ecce Homo são todos diferentes versões do esforço nietzschiano no sentido de articular o que torna alguns seres humanos notáveis, distintos, diferentes do resto do mundo. Se ele tem uma preocupação filosófica central, é esta. E ela o envolve com as mesmíssimas dificuldades que Platão enfrentou na República.

Em Para além de Bem e Mal, Nietzsche parece defender uma política aristocrática porque ele pensa, de forma controversa, que apenas a existência de distinções sociais pode garantir a realização do que ele tende a considerar como a meta última da política:

o desejo de sempre aumentar a distância no interior da própria alma, a elaboração de estados sempre mais elevados, mais raros, remotos, amplos, abrangentes, em suma, a elevação do tipo "homem", a contínua “autossuperação do homem” (JGB/BM 257, KSA 5.205).

Mais adiante, ele escreve que em certos momentos da 
Nehamas, A.

história o "indivíduo" aparece obrigado a dar-se a si mesmo as leis e a desenvolver artifícios e expedientes de autopreservação, autoaprimoramento e autorredenção (JGB/BM 262, KSA 5.214). "A alma nobre", Nietzsche afirma, "sabe que se encontra no alto" (JGB/BM 265, KSA 5.219). Ele continua:

- O que é nobre? O que significa hoje para nós a palavra "nobre"? Onde se revela, em que se reconhece, sob o pesado e anuviado céu do incipiente domínio da plebe, através do qual tudo fica opaco plúmbeo, o homem nobre? - Não são os atos que o apontam - os atos são sempre ambíguos, sempre insondáveis -; também não são as "obras". ... Não são as obras, é a fé que aqui decide, que aqui estabelece a hierarquia... alguma certeza fundamental que a alma nobre tem a respeito de si, algo que não se pode buscar, nem achar, e talvez tampouco perder. A alma nobre tem reverência por si mesma (JGB/BM 287, KSA 5.232).

Quando Nietzsche escreve assim, ficamos tentados a pensar que nobreza e heroísmo são tão somente estados da alma, disposições internas independentes de feitos e ações. Semelhante concepção quietista parece permitir que um ermitão, que se retira completamente do mundo, vive em total isolamento e morre para sempre desconhecido, pode ser um heroi individual tão grandioso quanto qualquer outro que se possa imaginar. É a estrutura psicológica correta que torna alguém o "tipo aprimorado" de ser humano que Nietzsche admira, independentemente do fato de alguém reconhecê-lo ou não. Sócrates poderia ter permanecido um escultor e nunca ter encontrado Platão, Montaigne poderia ter permanecido prefeito de Bourdeaux e nunca ter escrito os Ensaios, Napoleão poderia ter preferido ser fazendeiro em Corsica ao invés de se juntar à artilharia francesa: o esquecimento não os teria privado da grandeza. Mas isso não pode estar certo. Pois, como qualquer leitor da Genealogia da Moral sabe,

- Exigir da força que não se expresse como força... é tão absurdo quanto exigir da fraqueza que se expresse como força... Não existe

246 Cad. Nietzsche, Guarulhos/Porto Seguro, v.37, n.1, p. 242-268, 2016. 
"ser" por trás do fazer, do atuar, do devir; "o agente" é uma ficção acrescentada à ação - a ação é tudo $(G M / G M, \mathrm{I}, 13, \mathrm{KSA} 5.278)$.

O "interior", Nietzsche crê, não pode ser separado do "exterior". Sua tese é de que a alma, concebida como uma disposição interior bastante independente, e mesmo oposta ao comportamento de um indivíduo, é uma invenção que torna possível que pessoas que não se distinguem por nada possam convencer a si mesmas que sua ordinarice não é uma consequência necessária de sua natureza, mas o livre produto de sua escolha:

O sujeito (ou, falando de modo mais popular, a alma) foi até o momento o mais sólido artigo de fé sobre a terra, talvez por haver possibilitado à grande maioria dos mortais, aos fracos e oprimidos de toda espécie, enganar a si mesmos com a sublime falácia de interpretar a fraqueza como liberdade, e o seu ser-assim como mérito $(G M / G M, \mathrm{I}, 13$, KSA 5.278).

O mesmo princípio se aplica ao próprio Nietzsche e sua obra. Em seu estudo sobre o "individualismo heroico", Leslie Thiele faz a seguinte afirmação:

Os escritos que Nietzsche deixou são um testamento de seu entendimento da arte. Eles são, como todas as obras de arte, de importância secundária, são as relíquias de uma luta espiritual. A vida que as produziu permanece sendo a justificação de seu aparecimento; as obras elas mesmas são meramente os excrementos de uma experiência digerida ${ }^{4}$.

Se isto é verdade, Nietzsche seria o que ele é - o que quer que isso signifique exatamente - mesmo se nunca tivesse escrito uma palavra. Mas isto é impossível. A "vida" que produziu essas obras não foi vivida independentemente da sua escrita. A escrita foi parte fundamental da vida, não uma "relíquia" de uma "luta espiritual",

4 THIELE, Leslie Paul. Friedrich Nietzsche and the Politics of the Soul: A Study of Heroic Individualism. Princeton: Princeton University Press, 1990, p. 131. 
Nehamas, A.

mas a própria luta. A "experiência" de Nietzsche não precede essa escrita, a experiência está nela. As obras determinam quem Nietzsche é. A vida de Nietzsche não é uma justificativa de suas obras, mas, antes, em grande medida, o produto das mesmas. Mesmo em Para além de Bem e Mal, Nietzsche está ciente dessa ampla relação. A mesma seção na qual encontramos o argumento de que é a "fé" e não a obra que revela a nobreza contém também a seguinte passagem:

Entre artistas e eruditos encontram-se muitos que revelam, com suas obras, o quanto um anseio profundo os impele em direção ao que é nobre: mas precisamente este necessitar do que é nobre é radicalmente distinto das necessidades da alma nobre mesma, e inclusive um sintoma eloquente e perigoso da sua ausência ( $J G B / B M$ 287, KSA 5.232).

Se as coisas se passam desse modo, e se desconsiderarmos toda a conversa sobre a "fé",é a natureza das obras, afinal de contas, que revela se alguém é ou não é nobre. Se algumas obras denunciam o fato de que aqueles que os produzem carecem de nobreza, então aqueles que a possuem - já que eles devem, como afirmado na Genealogia, expressar sua nobreza de uma forma ou de outra - devem também produzir obras que revelam ou talvez até mesmo constituam sua nobreza.

A nobreza pode bem ser um traço da alma. Mas a alma, Nietzsche crê, não é uma substância independente do corpo. Ela é, possivelmente, a "estrutura social de impulsos e afetos" (JGB/BM 12, KSA 5.26), mas impulsos e afetos são constituídos na ação. Eles são aspectos da "vontade", mas a vontade não é nem livre nem não livre. Compulsão e total autodeterminação, Nietzsche escreve numa passagem bem conhecida, são ideias igualmente "mitológicas": "na vida real há apenas vontades fortes e fracas" (JGB/BM 21, KSA 5.35). A nobreza, portanto, se manifesta necessariamente na ação: almas nobres são aquelas que agem nobremente. Pode-se talvez argumentar que o estado psicológico da nobreza é a causa das ações 
que a manifestam, e que entre causa e efeito sempre pode intervir uma série de acidentes que impedem a realização do efeito. Mas Nietzsche não pode se permitir essa visão. A noção comum de causa é derivada, ele escreve, "do âmbito dos famosos 'fatos interiores', dos quais nenhum, até hoje, demonstrou ser real". "O povo" - continua a passagem da Genealogia que diz que o "feito" é tudo - "duplica a ação, na verdade; quando vê o corisco relampejar, isto é a ação da ação: põe o mesmo acontecimento como causa e depois como seu efeito" (GM/GM, I, 13, KSA 5.278).

Nobreza de alma e nobreza de ação não podem, portanto, ser separadas uma da outra. Ações nobres devem ser de um certo tipo, embora seja muito difícil dizer de qual: elas são contrárias àquelas que dão mostras de sua falta, como dizemos, e elas devem ser significativamente diferentes das ações comuns ao mundo em que se está. $\mathrm{O}$ indivíduo, que constitui "uma vida maior, mais múltipla e mais abrangente vive além da velha moral" (JGB/BM 262, KSA 5.214): isso é parte do que é "dar-se leis a si mesmo", criar seus próprios valores, o que é, para Nietzsche, o marco da grandeza. Alguém só é um indivíduo na medida em que (voltando às noções gregas com as quais começamos) é diferente, se destaca, se distingue do resto do mundo em que está, da multidão que Nietzsche dispensa com desprezo como "o rebanho".

É possível que algumas pessoas sejam realmente diferentes das demais e realizem ações que não têm precedentes, sem ao mesmo tempo serem notadas por isso? Do ponto de vista lógico, claro, essa possibilidade é bem real: Mendelssohn poderia nunca ter chegado a apreciar a música de Bach, negligenciada em sua época; a queima da Biblioteca de Alexandria talvez tenha nos privado das obras do maior tragediógrafo grego (agora anônimo); suponho que o inventor da roda, se é que houve tal pessoa, se qualifica como um bom candidato. Mas nós, como Nietzsche, estamos interessados na história. E eu não tenho certeza se no interior da história é possível ser diferente, quer 
Nehamas, A.

dizer, fazer a diferença e passar totalmente despercebido. Afinal, Bach veio a ser reconhecido, enquanto que a hipotética influência do tragediógrafo perdido (sendo que a influência está profundamente conectada com grandeza) agora se dissipou e parece pálida frente àquela de Ésquilo.

Vamos usar um exemplo antigo e vulgarizado para ilustrar este ponto. A árvore que cai na floresta bem pode produzir um som, mas se ninguém o escuta, seu som não faz diferença. Mas a queda da árvore, poder-se-ia replicar, pode ter as maiores consequências. Ao bloquear uma nascente, a árvore pode ter mudado para sempre o estado da floresta, o que pode ter feito com que uma cidade perdesse seu sustento, o que pode ter ocasionado a queda de um grande império. Tenho certeza de que tais coisas acontecem. Mas note-se que não está claro que podemos dizer que a árvore fez a diferença, já que fazer a diferença sempre requer uma alternativa concreta em relação à qual se faz a diferença. Pode parecer que a alternativa relevante neste contexto esteja representada pelo caso em que, não tendo a árvore caído, o império em questão não entraria em derrocada, pois deste modo a cidade não teria perdido seu sustento. Mas o fato é que não há um império "em questão": nós simplesmente não sabemos sobre qual império, cidade, nascente ou árvore estamos a falar. A história está cheia de eventos aleatórios do tipo representado por uma árvore que cai, e alguns desses eventos podem ser as ações das pessoas. Mas a diferença não é feita toda vez que algo acontece, o que é o tempo todo, mas apenas quando a história realmente muda de direção. E a história muda de direção apenas quando ela diverge de um curso que já havia tomado. Mas a história, como Nietzsche sabia, não tem direção em si mesma: "Nós inventamos o conceito de 'finalidade'; na verdade não há finalidade" (GD/CI, Os quatro grandes erros, 8, KSA 6.96). A história, então, muda de direção apenas na medida em que podemos discernir a mudança, já que a direção da qual ela diverge é uma direção na qual a encontrávamos em primeiro lugar.

$250 \mid$ Cad. Nietzsche, Guarulhos/Porto Seguro, v.37, n.1, p. 242-268, 2016. 
Nessa medida, portanto, grandes indivíduos são aqueles que fazem a diferença na história, e que são conhecidos por isso.

Fazer diferença é, portanto, necessário para ser um heroi. Mas é também suficiente? O que dizer daqueles que fazem uma diferença horrivel? Ademais, nós agora enfrentamos dois problemas correlatos. O primeiro é o problema da fama. Ser conhecido não é o mesmo que ser famoso? A fama [kleos] não é justamente aquilo que o heroi homérico persegue? Contudo, Nietzsche desdenha da fama, tanto no seu próprio caso ("Mas assim vivi sempre. Não tive desejo algum. Alguém que tendo completado quarenta e quatro anos pode dizer que nunca lutou por honras" - EH/EH, Por que sou tão inteligente, 9, KSA 6.293) quanto de forma geral, louvando aquele "heroísmo refinado, que desdenha se oferecer à adoração das massas, ao contrário do que faz seu irmão mais rude, e anda em silêncio através do mundo e para fora dele." (MA I/HH I 291, KSA 2.234). "A fama (e a aspiração à fama)," Leslie Thiele escreve, "é a marca de uma natureza mais baixa, de alguém capaz de ser apreciado pelo "rebanho"' Mas ser conhecido não é o equivalente a ser famoso se isso significa ser apreciado pelo rebanho e venerado pelas massas. Alguém também pode ser conhecido, por exemplo, devido a realizações que inspiram medo no rebanho e desconfiança nas massas. De todo modo, a fama deve manter-se distinta da admiração - alguém pode muito bem ser famoso em função de algo desprezível. Ou talvez alguém possa ser conhecido e admirado não por todos, mas apenas por aqueles que contam, ou seja, outros indivíduos que se engajam no mesmo tipo de atividade nobre.

Este último ponto leva diretamente ao nosso segundo problema. Todos que abominam "Hitler" pertencem necessariamente às massas? E como podemos identificar quem são os indivíduos nobres capazes de reconhecer o heroi sem saber de antemão o que é a nobreza? Pois se não sabemos o que constitui a nobreza, não estaremos aptos a dizer

5 THIELE, Leslie Paul, op. cit., p. 21. 
Nehamas, A.

se alguém é tido como nobre pelo tipo correto de pessoa ou pelo tipo errado de pessoa, o tipo não apto a distinguir o nobre do ignóbil, de qualquer modo. O problema do público apropriado do heroi, que Platão outrora resolveu imaginando uma cidade impossivelmente perfeita, é o problema de Nietzsche também ${ }^{6}$.

Ser nobre, de acordo com Nietzsche, é ter um certo tipo de alma: "O homem nobre", por exemplo, "honra em si o poderoso, e o que tem poder sobre si mesmo, que entende de falar e calar, que com prazer exerce rigor e dureza consigo e venera tudo que seja rigoroso e duro" (JGB/BM 260, KSA 5.208). Por mais difícil que seja reconhecer isto, eu devo confessar que as várias descrições nietzschianas da alma nobre são mais fracas, vagas, e constrangedoras do que qualquer coisa que ele tenha escrito. Elas dizem pouco e o pouco que elas dizem não é nem interessante nem muito útil. Mas mesmo se pusermos de lado esse problema, seremos confrontados por outro, ainda mais urgente.

Valores nobres, diz Nietzsche, dependem da divisa - "estranha e penosa para o gosto atual" - de que temos deveres somente perante nossos pares: de que frente aos seres de extração inferior, frente a tudo de estranho e alheio, pode-se agir ao bel-prazer, ou "como quiser o coração", e em todo caso "além de bem e mal". Mesmo que em seguida ele escreva, como Walter Kaufmann se regozijou em salientar, que "aqui piedade e sentimentos similares podem tomar lugar" (JGB/BM 260, KSA 5.208), permanece o fato de que "uma aristocracia boa e sã" aceita "com boa consciência o sacrifício de inúmeros homens que, por sua causa, devem ser oprimidos e

6 Outro paralelo sugere que a relação de Nietzsche com Platão é muito mais complexa do que acreditamos em geral: os diálogos socráticos de Platão supõem que apenas uma pessoa boa pode reconhecer outra, e que acercar-se de alguém que professa ensinar o que é areté pode causar o maior dano a menos que a pessoa em questão já saiba o que é a areté e seja capaz de defenderse contra concepções equívocas. Mas se essa pessoa já sabe o que é a areté, então ela não terá necessidade de acercar-se de tal professor! Ver Protágoras 313al-314c2 com Laques 189d3-190c6 e, para uma discussão do tema, cf. NEHAMAS, Alexander. The Art of Living. op. cit., p. 79-82.

252 | Cad. Nietzsche, Guarulhos/Porto Seguro, v.37, n.1, p. 242-268, 2016. 
reduzidos a seres incompletos, escravos, instrumentos" $(\mathrm{JGB} / \mathrm{BM}$ 258, KSA 5.206). Isto não é apenas um comentário pontual sobre classe social: "o egoísmo é a essência de uma alma nobre, quero dizer, aquela crença inamovível de que, a um ser 'tal como nós', outros seres têm de sujeitar-se por natureza, e a ele sacrificar-se" (JGB/BM 265, KSA 5.219).

A fé no valor instrumental e na dispensabilidade dos outros é o traço de nobreza que gera o problema que nos deixa em situação tão desconfortável, o problema do heroi do mal. Joachim Fest pode muito bem ter razão ao retratar Adolf Hitler como alguém que, apesar de seus ocasionais apelos a Nietzsche, não satisfez o critério nietzschiano de nobreza ${ }^{7}$. Keith Ansell-Pearson pode estar correto ao afirmar que o ressentimento é totalmente incompatível com uma alma nobre e que "Hitler foi um homem cujo ser estava permeado por sentimentos profundamente arraigados de ressentimento e venenosa vingança, e dificilmente ele poderia ser tido como um exemplo do indivíduo nobre nietzschiano"s. No entanto, embora Hitler possa ter tido o tipo inadequado de alma - o que quer que isso signifique - o mesmo não é necessariamente o caso para "Hitler". Nobreza e crueldade não são apenas compatíveis: elas parecem andar de mãos dadas segundo Nietzsche, e isso confere às suas posições as mais perturbadoras consequências éticas e políticas. A política, Nietzsche

7 Fest não examina a relação de Hitler e Nietzsche em maior detalhe, mesmo porque ele acredita que, de um ponto de vista intelectual, Wagner foi muito mais importante para Hitler que Nietzsche, embora em um determinado momento ele faça a observação - intimamente relacionada à presente discussão - de que Hitler "concordava com o dito de Nietzsche segundo o qual uma nação não é nada mais que um atalho da natureza para produzir uns poucos homens importantes. 'Gênios do tipo extraordinário', ele destacou, com um olhar oblíquo a si mesmo, "não podem mostrar consideração pela humanidade normal'. Sua visão superior, sua missão elevada, justificariam qualquer dureza" (FEST, Joachim C. Hitler. Rio de Janeiro: Nova Fronteira, 1976, p. 531). Mas o retrato de Hitler que emerge de seu estudo detalhado não é congruente com a imagem nietzschiana (assumidamente vaga) de nobreza. O Prólogo de Fest, "Hitler e a Grandeza na História", também é relevante para nossas questões.

8 ANSELL-PEARSON, Keith. An Introduction to Nietzsche as Political Thinker. Cambridge: Cambridge University Press, 1994, p. 33. 
Nehamas, A.

parece crer, deveria ter como meta a produção de indivíduos nobres, e indivíduos nobres não apenas não devem ser criticados por sua crueldade; pelo contrário, eles devem frequentemente ser louvados e admirados em razão disso.

A questão, portanto, é o que fazer de uma filosofia que parece dizer que deveríamos valorizar a crueldade:

apropriação, ofensa, sujeição do que é estranho e mais fraco, opressão, dureza, imposição de formas próprias, incorporação e, no mínimo e mais comedido, exploração; a exploração... faz parte da essência do que vive, como função orgânica básica, é uma consequência da própria vontade de poder, que é precisamente vontade de vida (JGB/BM 259, KSA 5.207).

Qual é a reação adequada a tal visão da vida e do mundo? Nós podemos, é claro, criticar a crueldade, a apropriação, a ofensa, e tudo mais, mas apenas quando elas emergem de naturezas ignóbeis e estão a serviço de propósitos ignóbeis. Como tudo mais, de acordo com Nietzsche, elas não são erradas em si mesmas, mas apenas com relação a suas origens e finalidades. Parece que não há ponto algum a ser discutido quando, como acontece com o Hitler ou o Stálin históricos, a crueldade atinge o nível de magnitude que torna seus propósitos irrelevantes, quando a repulsa pelos feitos em si mesmos que emergem dessa crueldade torna-se a atitude apropriada, independentemente de quaisquer outras considerações. Isso independe, é claro, do fato de que aqueles que se engajam em tais feitos não são imorais - já que nada é imoral de acordo com Nietzsche -; nem mesmo é o caso de podermos descrevê-los como desumanos, já que todos esses traços, Nietzsche alegaria em semelhante contexto, são traços da própria vontade de vida e, portanto, manifestações, ainda que por demais desconcertantes, daquilo que, precisamente, é do âmbito do poder humano.

Pode-se pensar, e eu pensei assim ocasionalmente, que essa preocupação em criticar e julgar seria em si mesma signo de uma 
natureza ignóbil - algo que seria melhor deixar para trás e não nos preocuparmos. Nietzsche, afinal, escreve que ele "exige" do filósofo "colocar-se além do bem e do mal" (GD/CI, Os "melhoradores" da humanidade, 1, KSA 6.98). Mas o juízo moral, como Nietzsche bem sabe, é apenas um tipo de juízo. Em sua discussão com Sainte Beuve, ele virtualmente define filosofia como "a tarefa de julgar em todas as questões principais" (GD/CI, Excursões de um extemporâneo, 3, KSA 6.112). Nietzsche foi um juiz inveterado de tudo a seu redor. Ele também admirava a autorreferência. Ele portanto poderia apreciar o que eu agora me proponho a fazer, que é aplicar o que ele considera ser a tarefa da filosofia à sua própria filosofia. Como devemos julgar - não, é claro, de um ponto de vista moral - uma filosofia que se recusa a condenar em termos absolutos qualquer manifestação da crueldade ou injustiça? Seria esta uma filosofia nobre, uma filosofia que podemos admirar?

Tenho muita simpatia pelo imoralismo de Nietzsche, sua ideia de que as qualidades de bem e mal estão intimamente interconectadas. Por vezes ele parece acreditar que quem quer que tenha uma grande virtude também terá necessariamente um grande vício. Mais frequentemente, ele afirma que o mesmíssimo traço psicológico constitui um vício em um contexto e uma virtude em outro. Toda urgência beligerante que é essencial para estabelecer um novo estado, por exemplo, torna-se perigosa uma vez que tal estado já esteja instalado; ela então é renomeada, reconceitualizada como um vício, e reprimida (JGB/BM 201, KSA 5.121). A honestidade é uma expressão intelectual, sublimada, do mesmo impulso que em outros contextos se manifesta como crueldade (JGB/BM 230, KSA 5.167) - e assim, de fato, se passa com a alta cultura em geral (JGB/BM 229, KSA 5.165), e aqui o argumento de Nietzsche é consistente?.

9 Sobre a identidade essencial entre moral e imoral, bem e mal, ver também: $J G B / B M 2,259$, KSA 5.16, 207; Nachlass/FP 10 [154], KSA 12.542. 
Nehamas, A.

Se Nietzsche está certo em que as qualidades de bem e mal estão assim conectadas, a forma correta de tratar os impulsos que resultam em imoralidade não é tentar eliminá-los ou reprimi-los, mas sublimá-los e espiritualizá-los, usá-los para produzir metas admiráveis. Nietzsche é claro:

A espiritualização da sensualidade chama-se amor... a espiritualização da inimizade... consiste em compreender profundamente o valor de possuir inimigos [inclusive inimigos internos: "somos fecundos apenas ao preço de sermos ricos em antagonismos"]... também no âmbito político, [escreve ele ingenuamente], a inimizade se tornou mais espiritual $(G D / C I$, Moral como Antinatureza, 3, KSA 6.84).

Por outro lado, tentar destruir "as paixões e os desejos apenas para evitar sua estupidez e as desagradáveis consequências de sua estupidez, isso nos parece, hoje, apenas uma forma aguda de estupidez" (GD/CI, Moral como Antinatureza, 1, KSA 6.82). No entanto, é justamente isso o que faria a "igreja", que ele identifica com a moralidade:

A igreja combate a paixão com a extirpação em todo sentido: sua prática, sua "cura" é o castracionismo. Ela jamais pergunta: "Como espiritualizar, embelezar, divinizar um desejo?" - em todas as épocas, ao disciplinar, ela pôs a ênfase na erradicação (da sensualidade, do orgulho, da avidez de domínio, da cupidez, da ânsia de vingança). - Mas atacar as paixões pela raiz significa atacar a vida pela raiz: a prática da Igreja é hostil à vida... (GD/CI, Moral como Antinatureza, 1, KSA 6.82).

Nietzsche às vezes escreve, numa veia quase moralista, que "negar" ou ser "hostil" à vida, é simplesmente errado (Nachlass/FP 15 [113], KSA 13.471). Mais frequentemente, ele argumenta que é uma ação que derrota a si mesma, porque, com seu senso psicológico inigualável, ele vê que o esforço para extirpar as paixões requer as mesmíssimas paixões que estão sendo extirpadas. O esforço para eliminar a paixão requer seu exercício: se a crueldade, por exemplo, 
é uma paixão natural, nós podemos suprimi-la apenas ao nos permitir a crueldade. Nietzsche, em contraste com a moralidade tal qual ele a entende, não se importa: tal comportamento é crueldade sublimada. Mas ele também aceita a consequência de sua visão: crueldade sublimada, em situações particulares, bem pode irromper nas suas formas mais grosseiras e horríveis. Num contexto semelhante, ele escreve:

Pode-se ter completa razão, ao guardar temor e se manter em guarda contra a besta loura que há no fundo de toda raça nobre: mas quem não preferiria mil vezes temer, podendo ao mesmo tempo admirar, a não temer, mas não mais poder se livrar da visão asquerosa dos malogrados, atrofiados, amargurados, envenenados? (GM/GM, I, 11, KSA 5.274; cf. I, 12, KSA 5.277).

Mas esse é justamente nosso problema. Podemos admirar uma filosofia totalmente sem limites? Deixe-nos voltar a Hitler (sem aspas). Podemos admirar uma filosofia que talvez sugira que o que havia de errado com o extermínio metódico, a sangue frio, de seis milhões de pessoas é o fato de que ele foi motivado pelo ressentimento e pela crença absurda de que esses milhões de pessoas constituíam um perigo para sua raça? Não é terrivelmente óbvio que tal ação teria sido errada quaisquer que fossem os motivos e crenças em que se baseasse? Devemos ser cuidadosos aqui. Nietzsche escreve: "Restauração da 'natureza': uma ação em si mesma é perfeitamente desprovida de valor: tudo depende de quem a executa. O mesmo 'crime' em certo caso pode ser o maior privilégio, em outro um estigma" (Nachlass/ FP 10 [46], KSA 12.477; cf. JGB/BM 30, KSA 5.48). Podemos tentar imaginar que seis milhões de pessoas pudessem de fato representar um perigo para nós, que seria uma questão de nós ou eles, e que nós nos engajaríamos numa guerra contra eles que teria resultado em seu extermínio. Tal ação pode parecer justificável, e isso talvez pareça contar a favor da afirmação de Nietzsche: a mesma ação - a destruição de seis milhões de pessoas - pode ser aceita em um caso 
Nehamas, A.

e condenada no outro. Mas a situação é mais complicada. A questão é como devemos descrever uma ação uma vez que abstraímos o agente que a executou (e portanto abstraímos os motivos e finalidades originais). No presente caso, creio eu, se a alternativa que estamos imaginando tiver que ser "a mesma ação" dos nazistas tentando exterminar os judeus, tal ação deve ser pelo menos tão metódica e fria quanto a deles. Isto para mim parece excluir o caso de guerra como o entendemos em geral. Isso também sugere que é muito improvável que as pessoas em questão seriam um perigo para nós em qualquer sentido real, já que nossa habilidade para exterminá-los da forma como os judeus foram exterminados sugere precisamente que temos um imenso poder sobre eles.

Um nietzschiano deve se recusar a condenar qualquer manifestação de crueldade "em si"? Eu não posso acreditar que algumas instâncias de crueldade são de tal qualidade que as tornaria categoricamente diferentes do resto, de tal modo que elas jamais poderiam, em quaisquer contextos, ser louváveis? Nietzsche parece dizer que eu não posso:

O conceito de "ação condenável" traz dificuldades. Nada do que acontece em geral pode ser em si condenável: pois se poderia não querer afastá-lo: pois cada coisa está tão ligada com tudo o mais, que querer excluir algo significa excluir tudo. Uma ação condenável significa: um mundo condenado em geral... (Nachlass/FP 14 [31], KSA 13.234) ${ }^{\mathbf{1 0}}$.

Talvez mudar a escala do exemplo possa permitir uma compreensão mais clara do ponto. Suponhamos que eu viva sob um

10 A passagem continua, trazendo uma virada complicada para essa linha de pensamento: "E ainda: em um mundo condenado também o condenar seria condenável... A consequência de uma maneira de pensar que tudo reprova seria uma práxis que tudo ratifica... Caso o devir seja um grande anel, então cada coisa é igualmente valiosa, eterna e necessária. - Em todas as correlações de sim e não, de preferência e rejeição, amor e ódio exprimem tão somente uma perspectiva, um interesse de determinados tipos de vida: tudo o que é, em si, pronuncia o sim" (Nachlass/FP 14 [31], KSA 13.234). A última parte desse texto deve ser contrastada com outras passagens: cf. Nachlass/FP 15 [113], KSA 13.471 e FW/GS 344, KSA 3.74, discutidas abaixo.

258 Cad. Nietzsche, Guarulhos/Porto Seguro, v.37, n.1, p. 242-268, 2016. 
regime brutalmente opressor. Um oficial foi assassinado. A polícia apanha aleatoriamente uma mulher completamente inocente, na rua. Eles a torturam na praça e podem chegar a matá-la por retaliação. Eu assisto a cena, com um misto de fascinação e horror comum a tais experiências. Eu estou tentado a salvá-la. Eu sei que não posso, e que qualquer esforço fará com que ambos morram da mesma forma - talvez provoque o assassinato de outros inclusive. Eu me abstenho de agir. O que eu faço é razoável - mas não correto. Talvez eu tenha a obrigação de tentar salvar aquela mulher: não é óbvio que tenhamos o dever de ser santos morais. Mas ainda assim, eu me sinto culpado e envergonhado.

É errado sentir-se assim? Creio que não. Eu creio que em tais situações nunca se pode ter certeza de que não intervir é correto, mesmo se podemos entender facilmente por que quase ninguém interviria. Eu creio que cálculos utilitários sobre colocar mais pessoas em perigo ultrapassam o que está em jogo aqui, seria expressão de má-fé. Por quê? Porque penso que o fato de a polícia ter escolhido aquela mulher e não eu para semelhante propósito é algo absolutamente acidental. Nada de relevante me distingue daquela mulher: simplesmente aconteceu de eles a escolherem, e não a mim. Nem mesmo tenho certeza se, caso eu estivesse no lugar dela, eu teria pensado que alguém deveria tentar me salvar. Mas tenho certeza de que eu pensaria que eles deveriam sentir-se culpados e envergonhados por não tentarem fazê-lo. Claro, aqui e em inúmeras outras situações da vida há um elemento que Bernard Williams chamou de "sorte moral": talvez a minha vida se desdobre de tal forma que um dia, retrospectivamente, eu possa ser capaz de justificar o fato de não ter feito nada para salvar a vida daquela mulher desconhecida ${ }^{11}$. Mas na medida em que eu não posso justificá-lo, eu devo lamentar e, no sentido nietzschiano, "condenar" o fato de

11 Ver o ensaio homônimo na coletânea de WILLIAMS, Bernard. Moral Luck. Cambridge: Cambridge University Press, 1981, p. 20-39. 
Nehamas, A.

ter agido como agi.

Pode-se dizer o mesmo dos judeus. Seu extermínio tinha algo de essencialmente fortuito. Já que eles eram inocentes, o que lhes aconteceu poderia ter acontecido a qualquer um: o fato de serem judeus, naquele contexto, não é uma consideração relevante; em semelhante contexto, somos todos judeus, ou negros, ou kosovares. Mas a enormidade do extermínio dos judeus, pela diferença de escala, introduz um fator radicalmente diferente: é difícil imaginar qualquer desdobramento possível na vida de alguém que pudesse vir a autorizá-lo a justificar um dano de tal magnitude. E sem essa justificativa, a ação torna-se condenável "em si", uma ação que nunca deveria ter ocorrido.

Assim como as ações que temos o dever de impedir não deveriam nunca ter ocorrido e são condenáveis em si, do mesmo modo as ações que temos o dever de realizar são admiráveis, por mais que elas se revelem ações tolas e ineficazes e por mais que apenas raramente possamos realizá-las. No entanto, como temos visto, Nietzsche afirma que é "da essência de uma alma nobre" ter "aquela crença inamovível de que, a um ser 'tal como nós', outros seres têm de sujeitar-se por natureza, e a ele sacrificar-se" (JGB/BM 265, KSA 5.219), que "apenas frente aos iguais existem deveres" (JGB/BM 260, KSA 5.208). Mas quando o que nos separa dos outros é totalmente fortuito, como nas situações que discutimos, não há fundamento para pensar que "nós" somos diferentes daqueles outros, que eles não são nossos iguais. Aqueles que contam como nossos iguais é algo que pode variar conforme o contexto.

$\mathrm{O}$ que significa dizer que as diferenças entre as pessoas são fortuitas ou acidentais, se Nietzsche parece acreditar que não há diferenças entre propriedades essenciais ou acidentais, que algo é "a soma de seus efeitos"12? A distinção, como a uso aqui, não

12 Discuti essa visão de Nietzsche no capítulo 3 de Nietzsche: Life as Literature. Cambridge, Mass.: Harvard University Press, 1985.

$260 \mid$ Cad. Nietzsche, Guarulhos/Porto Seguro, v.37, n.1, p. 242-268, 2016. 
caracteriza o status metafísico das propriedades; ela é antes uma distinção entre por um lado aquelas propriedades que posso tomar como realizações minhas, como traços que tornei meus, e que são a base a partir da qual construí a mim mesmo e que constituem, portanto, sob quaisquer parâmetros, meus próprios méritos, e por outro lado aqueles traços que não têm tais características e que eu meramente possuo ${ }^{13}$. Estar a seis passos de distância da mulher que a polícia prendeu é uma diferença fortuita entre nós, a menos que minha vida acabe por mudar de tal forma que esse evento em si torne-se uma razão de ela ser admirável ou valorosa. Não está claro que qualquer realização desse tipo possa tornar o fato de eu não ter sido eliminado pelos nazistas em uma diferença irrelevante entre eu mesmo e aqueles que o foram. No mínimo, nunca poderei ter certeza de que eles não seriam meus iguais.

Acreditar que nossos iguais são um único grupo fixo é pensar que nós temos um status especial que confere um valor especial a nossas ações, quaisquer que sejam. $\mathrm{O}$ regime antigo pode ter pensado assim. Os aristocratas "sadios" de Nietzsche, seja da aristocracia social ou espiritual, talvez concordassem. Mas essa atitude - e esta é minha afirmação central neste ensaio - é inconsistente com sua visão de que o "sujeito" não precede, determina, ou causa suas ações, mas na verdade é constituído por elas: “o povo duplica a ação, na verdade quando vê o corisco relampejar, isto é a ação da ação: põe o mesmo acontecimento como causa e depois como efeito" (GM/GM, I, 13, KSA 5.278; Nachlass/FP 2 [84], KSA 12.103). São as ações que conferem status, e não o contrário, como Nietzsche às vezes pensa quando está preocupado com a nobreza: é exatamente isso que torna

13 Veremos nos parágrafos finais desse ensaio que há uma distinção da qual Nietzsche depende de forma crucial para seu ataque à moral "escrava" na Genealogia da Moral, embora, devo admitir, o vocabulário dele aqui é contrário ao meu: ele escreve que os "fracos" devem interpretar mal sua fraqueza, "isto é, seu ser ... [como] um empreendimento voluntário" (GM/GM, I, 13, KSA 5.278), enquanto eu quero afirmar que "feitos" são finalmente o que constitui a essência de uma pessoa. Eu creio que essa diferença é simplesmente terminológica. 
Nehamas, A.

sua descrição da nobreza tão insatisfatória. Os herois homéricos da Genealogia podem muito bem ter acreditado que eram capazes de feitos aos quais eles, e somente eles, tinham o direito. Mas se Aquiles tivesse permanecido se escondendo em roupas de mulheres para evitar a guerra em Troia, ele teria provado que não era um heroi e que não tinha direito aos feitos que enfim realizou (os quais, é claro, não teria realizado caso ficasse em casa). Nós podemos pensar que somos diferentes de pessoas cujas circunstâncias diferem das nossas devido a um simples acidente apenas se nós nos separamos das nossas ações, pensando que quem nós somos é algo muito superior do que o que fazemos, algo que pode determinar independentemente o caráter e valor de nossos feitos. Quem "nós" somos, quem nossos "iguais" podem ser, é igualmente uma questão de perspectiva, podendo mudar na medida em que nossas circunstâncias mudam, mas isso Nietzsche não foi capaz de perceber. "A ordem hierárquica” é compatível com muitos círculos de deveres, e pode ser que haja alguns deles que, em algumas circunstâncias extremas, são deveres que temos em relação a absolutamente quaisquer pessoas. Tais deveres podem governar uma pequena parte de nossas interações com os outros: o que é considerado uma ação moral, eu acredito, é um elemento limitado na vida ética humana e tem pouco a ver com nossa "essência racional". Esse elemento governa aquelas situações em que não há razão para pensarmos que somos diferentes do resto do mundo. Mas tais diferenças são contextuais, e as situações que elas fazem emergir não esgotam o leque de nossas interações, diferentemente do que somos tentados a pensar sob a influência da reflexão kantiana.

Nietzsche considerava a moralidade perigosa porque ela tenta impor o mesmo código de comportamento a todos, dificultando a ação de herois imoralistas, e afirmava que enquanto "princípio básico $d a$ sociedade, ele prontamente se revelaria como aquilo que é: vontade de negação da vida, princípio de dissolução e decadência" (JGB/ $B M$ 259, KSA 5.207). Creio, em concordância com Nietzsche, que 
princípios morais não podem, não deveriam e de fato não governam todas as nossas relações mútuas, e que em geral não são uma boa base para a prática da política. Mas eu também creio, contra Nietzsche, que a intuição de Kant sobre nosso senso de solidariedade com outros membros de nossa espécie precisa manter seu lugar na economia de nossa vida, mesmo que não pelas razões apontadas por Kant. Objetividade, diz Nietzsche em uma passagem bastante conhecida, não é "contemplação desinteressada", mas a habilidade de ver cada coisa a partir de muitos pontos de vista, a habilidade de "saber utilizar em prol do conhecimento a diversidade de perspectivas e interpretações afetivas" (GM/GM, III, 12, KSA 5.363; GD/CI, O que falta aos alemães, 6, KSA 6.108). Ele aplicou essa ideia à sua própria análise da moral cristã, para a qual disse tanto Sim - em razão dos muitos que dela precisam - e Não - em razão dos poucos que dela não precisam. Mas ele não foi longe o bastante, pois ele jamais foi capaz de perceber que pode haver situações particulares, específicas, talvez mesmo extraordinárias nas quais considerações morais podem ser apropriadas mesmo para aqueles poucos que conseguem viver além de bem e mal. Ele não viu que o erro da moralidade, que

toma o bem e o mal como realidades que estão em contradição entre si (não como conceitos de valor complementares, o que seria a verdade), aconselha que se tome o partido do bem, exige que o bem renuncie e resista ao mal até a última raiz - com isso ela nega a vida, que possui em todos os seus instintos tanto o sim quanto o não (Nachlass/FP 15 [113], KSA 13.471).

é um erro que ele mesmo pode ter cometido quando insistiu que não há, absolutamente, qualquer situação em que os princípios morais poderiam constranger seus próprios herois. Ele não viu que ao restringir o âmbito da vida no qual a moralidade é relevante, ele poderia vê-la ainda por uma outra perspectiva, aumentar a objetividade de sua abordagem, tornar-se apto a dizer Sim e Não 
Nehamas, A.

à moral.

"Sim" e "Não" são ambos essenciais ao pensamento nietzschiano sobre valores: "Todo naturalismo na moral", ele escreve, "ou seja, toda moral sadia, é dominada por um instinto de vida - algum mandamento da vida é preenchido por determinado cânon de "deves' e "não deves"” (GD/CI, Moral como antinatureza, 4, KSA 6.85). No parágrafo 344 de $A$ gaia ciência, numa passagem bastante conhecida, ele nega o valor incondicional da verdade com base em que na vida "tanto a verdade quanto a inverdade constantemente se mostram úteis" ( $F W /$ $G C$ 344, KSA 3.574). Sua rejeição absoluta das considerações morais em benefício de seus herois nobres pode no fim das contas não se acomodar muito bem com sua abordagem geral. E se estou certo ao apontar que Nietzsche, para rejeitar completamente as considerações morais, deve necessariamente pressupor uma separação de agente e ação, vem imediatamente à tona o que há de deliciosamente irônico nessa rejeição: para negar incondicionalmente a moral (que é, segundo suas próprias bases, o modo moralista de negar), ele precisa apelar justamente para a distinção que ele acredita ser a grande invenção da própria moralidade! Pois ele argumenta que a moralidade só pode colocar sua exigência absurda de que a força se expresse como fraqueza, ao mesmo tempo em que reinterpreta a fraqueza como um produto da escolha, na medida em que ela distingue entre o agente e a ação:

como se a fraqueza mesma dos fracos - isto é, seu ser, sua atividade, toda a sua inevitável, irremovível realidade - fosse um empreendimento voluntário, algo desejado, escolhido, um feito, um mérito... essa espécie de homem necessita crer no "sujeito" indiferente e livre para escolher. O sujeito (ou, falando de modo mais popular, a alma) foi até o momento o mais sólido artigo de fé sobre a terra, talvez por haver possibilitado à grande maioria dos mortais, aos fracos e oprimidos de toda espécie, enganar a si mesmos com a sublime falácia de interpretar a fraqueza como liberdade, e o seu ser-assim como mérito (GM/GM, I, 13, KSA 5.278).

264 Cad. Nietzsche, Guarulhos/Porto Seguro, v.37, n.1, p. 242-268, 2016. 
Mas esse modo de pensar também pode proceder, em certas circunstâncias, da direção oposta. Quando, por exemplo, me sinto justificado ao discriminar você porque minha pele é branca enquanto a sua não é, foco num traço que é simplesmente parte do meu "ser assim e assim" e o considero um mérito, uma realização, o tipo de coisa que seria o resultado de força e escolha, independentemente de qualquer coisa que eu tenha de fato realizado. Digo, portanto, que quem eu sou - neste caso, branco - confere a mim e a outros como eu um valor à parte de qualquer coisa que façamos, que isso confere valor a qualquer coisa que façamos, e que a ausência desse traço em você impede que seus feitos, quaisquer que sejam, tenham um valor que possa alguma vez igualar o meu. Mas diferentemente do talento, por exemplo, que é tanto individual quanto algo que se esgota na realização, a cor da pele por si não assinala uma realização e, portanto, não envolve mérito. Se não é um mérito, ela não estabelece nenhuma distinção entre nós: nesse contexto, somos ambos brancos, e somos ambos negros. Somos iguais. Tenho deveres perante você do mesmo modo que tenho deveres perante todos os meus iguais, nos vários contextos em que me encontro. $\mathrm{O}$ que quer que seja além disso, a nobreza é multidimensional. Um de seus aspectos é a habilidade de se dar conta de que nem tudo em uma pessoa nobre é nobre, exceto talvez aquela habilidade mesma. Este não é um argumento que pretenda convencer um racista ou um Hitler. Mas é construído com o intuito de convencer um nietzschiano, talvez até mesmo um "Hitler", que deseja se manter consistente na recusa de separar o agente da ação.

Se coisas se passam desse modo, eu não preciso fazer um juízo moral da filosofia de Nietzsche para discordar dele: "Hitler" talvez possa criar valores e satisfazer os (vagos) critérios psicológicos de Nietzsche para a nobreza, mas ainda assim ele pode ser terrivelmente imoral, agindo de uma forma que ninguém jamais deveria agir, seja ele quem for e em quaisquer que sejam as circunstâncias. É bastante 
Nehamas, A.

conhecida a declaração de Nietzsche de que a moralidade tem uma base imoral: "todos os meios pelos quais, até hoje, quis-se tornar moral a humanidade foram fundamentalmente imorais" (GD/CI, Os "melhoradores" da humanidade, 5, KSA 6.102); "a moralidade, ela mesma, é uma forma de imoralidade" (Nachlass/FP 14 [137], KSA 13.321; 14 [134], KSA 13.317). Argumentei contra ele no sentido de que a rejeição absoluta da moralidade tem uma base moral. Seu desejo de abandonar completamente as considerações morais, um dogmatismo do próprio Nietzsche, requer que ele apele para os mesmos meios que ele acredita que todo dogmatismo, particularmente o da moralidade, está obrigado a usar para justificar suas prescrições e proibições absolutas. A filosofia de Nietzsche, portanto, é admirável? Na medida em que se recusa a rejeitar incondicionalmente o heroi do mal a resposta é Não. Mas na medida em que ela mesma nos fornece os meios não morais para rejeitar sua própria recusa a resposta é Sim. A filosofia de Nietzsche, como tudo mais na vida, inclusive a moral, conduz, portanto, a um Não e a um Sim. Ao refutá-la, nós a afirmamos. Seu erro é um testemunho de sua verdade ${ }^{14}$.

\begin{abstract}
This article deals with the limits of Nietzsche's immoralism, taking as a central thread the figure of the hero of the evil. It defends the thesis that there is a limit to this immoralism, since some questions must remain in the sphere of the moral treatment, in the lightly pejorative sense given to the term among the critics of the morality.
\end{abstract}

Keywords: heroi - immoralism - virtue - fama

14 Este artigo foi originalmente apresentado em uma Conferência Spindel na Universidade do Tennessee em 1998. Sou grato a Jacqueline Scott, que organizou a conferência bem como a Florian Becker, Akeel Bilgrami, Maudemarie Clark, Keith Donoghue, Mathias Risse e Robert Gooding-Williams, cujos comentários me levaram a uma série de correções. Uma versão prévia do artigo foi publicada em Nietzsche: Godfather of Fascism? Editado por Jacob Golomb e Richard Wistrich (Princeton: Princeton University Press, 2002) e posteriormente incluído na edição de Iyyun, em honra às contribuições de Jacob para nossa disciplina.

$266 \mid$ Cad. Nietzsche, Guarulhos/Porto Seguro, v.37, n.1, p. 242-268, 2016. 


\section{Referências bibliográficas}

ANSELL-PEARSON, Keith. An Introduction to Nietzsche as Political Thinker. Cambridge: Cambridge University Press, 1994.

FEST, Joachim C. Hitler. Rio de Janeiro: Nova Fronteira, 1976.

NEHAMAS, Alexander. Nietzsche: Life as Literature.Cambridge, Mass.: Harvard University Press, 1985.

.The Art of Living: Socratic Reflections from Plato to Foucault. Berkeley: University of California Press, 1998.

NIETZSCHE, Friedrich. Sämtliche Werke. Kritische Studienausgabe, Berlim: Walter de Gruyter \& Co., 1967/1978. 15 vols. (Organizada por Giorgio Colli e Mazzino Montinari).

. Humano, demasiado humano. Trad. de Paulo César de Souza. São Paulo: Cia. das Letras, 2000.

. A gaia Ciência. Trad. de Paulo César de Souza. São Paulo: Cia. das Letras, 2001.

. Além do bem e do mal. Trad. de Paulo César de Souza. São Paulo: Cia. das Letras, 1999.

- Genealogia da moral. Trad. de Paulo César de Souza. São Paulo: Cia. das Letras, 1998.

. Crepúsculo dos ídolos. Trad. de Paulo César de Souza. São Paulo: Cia. das Letras, 2006.

PLATÃO. Protágoras. Trad. de Carlos Alberto Nunes. Ed. da UFPA, 2002. Laquete. Trad. de Carlos Alberto Nunes. Ed. da UFPA, 2007.

STERN, J. P. A Study of Nietzsche. Cambridge: Cambridge University Press, 1979.

THIELE, Leslie Paul. Friedrich Nietzsche and the Politics of the Soul: A Study of Heroic Individualism. Princeton: Princeton University Press, 1990. 
Nehamas, A.

WILLIAMS, Bernard. Moral Luck. Cambridge: Cambridge University Press, 1981, p. 20-39.

Artigo recebido para publicação em 12/09/2015. Artigo aceito para publicação em 09/12/2015. 